\title{
Children's Idea about Cigarettes and Smoking
}

\author{
Poorandokht Afshari, ${ }^{1}$ Marzieh Rakhsh Khorshid, ${ }^{2}$ Mahdis Vakili, $,{ }^{3,4},{ }^{*}$ Maryam Jahandideh, ${ }^{1}$ and
}

Mehrnaz Ahmadi ${ }^{5}$

${ }^{1}$ School of Nursing and Midwifery, Ahvaz Jundishapur University of Medical Sciences, Ahvaz, IR Iran

${ }^{2}$ School of Nursing and Midwifery, Zahedan University of Medical Sciences, Zahedan, IR Iran

${ }^{3}$ Student Research Committee, Ahvaz Jundishapur University of Medical Sciences, Ahvaz, IR Iran

${ }^{4}$ Department of Nutrition, Para Medicine School, Ahvaz Jundishapur University of Medical Sciences, Ahvaz, IR Iran

${ }^{5}$ Master of Nursing, School of Nursing and Midwifery, Ahvaz Jundishapur University of Medical Sciences, Ahvaz, IR Iran

"Corresponding author: Mahdis Vakili, Student Research Committee, Ahvaz Jundishapur University of Medical Sciences, Ahvaz, IR Iran. Tel: +98-9168300423, Fax: +98-6133375717, E-mail: mahdisvakili@ymail.com

Received 2015 July 05; Revised 2016 March 09; Accepted 2016 April 23.

\begin{abstract}
Background: Tobacco smoking is attributed to pediatric disease and pediatric epidemics. This study aimed to indicate the attitudes of four- to six-year-old children toward cigarettes.

Methods: This cross sectional study was conducted by a questionnaire in 2011. Hundred and forty-five, children, aged four to six years, were randomly selected from eight kindergartens located in all four areas of Ahvaz. Descriptive statistics was used to analyze demographic data, Chi-square test to compare qualitative variables and Pearson correlation coefficient to compare quantitative data.

Results: Results of the study showed that $76.4 \%$ of children knew what a cigarette is; $41.2 \%$ had talked about smoking with their parents; $1.4 \%$ had asked to buy one due to the attractive appearance of cigarette packs; $27.8 \%$ imitated the act of smoking. Children's attitude toward smoking showed that $1.4 \%$ of them took smoking as a good act, $91.4 \%$ believed that smoking was a bad act and $7.1 \%$ had no idea about smoking.

Conclusions: Since parents' behaviors affect their children, it is advisable to implement effective interventional programs to increase parents' awareness about smoking and its harmful environmental effects.
\end{abstract}

Keywords: Children's Idea, Cigarette, Chronic Disease

\section{Background}

Among the drugs, cigarettes are the most available and cheap ones; therefore, everyone can obtain it without any social indecency (1). There are numerous documents showing that smoking can cause many diseases such as cancer, respiratory, cardiovascular and gastrointestinal diseases and gingivitis in humans (2). Smoking and drinking alcohol, as environmental factors, have severe effects on liver (3). According to the world health organization (WHO), in 2015 smoking compare to HIV/AIDS had 50\% higher mortality and caused $10 \%$ of all deaths (4).

According to statistics released by WHO, there are 1.25 billion smokers worldwide that nearly two-thirds of these people live in the developing countries (5). Asian smokers are approximately $22 \%$ of their population and in Africa, about $42 \%$ (6).

According to the latest statistics published by the Iranian Ministry of Health, $15 \%$ of the population or 11 million people are smokers in the country (7).
Smoking and its related diseases, account for about $20 \%$ of deaths in the United States and impose a cost of US\$ 2.97 billion a year to the country (8).

The main cause of chronic obstructive pulmonary disease (COPD) is smoking. COPD is the fourth leading cause of death due to smoking in the USA; and by 2020 is predicted to be the third factor (9).

Shaokohi et al. declared that $3.16 \%$ of elderly people in Ilam, Iran, were addicted to smoking at that time; $41 \%$ reported a history of smoking, $22.5 \%$ of these people had problem with breathing that $3.8 \%$ of these people used bronchodilator sprays and $1.2 \%$ used oxygen capsule (10). There is considerable evidence that in the last decade tobacco advertising mainly targeted teenagers and young adults (11). Tobacco consumption worldwide is attributed to infant morbidity and pediatric epidemics. One out of every four smoker students aged 13 - 15 years, started smoking before 10 for the first time (12). Based on the WHO reports, the prevalence of smoking among 15-year-old students is more than 15\% (13). In Iran, official reports indicate that 
six-hundred-thousand students are addicted to cigarettes in the country (14). One of the main strategies to reduce the prevalence of this behavior is to prevent children to test this product. Therefore, the knowledge of prevalence and patterns of smoking start up in adolescents and their attitude toward this issue is a critical factor (8).

The study by Riahi et al. in Qaemshahr, Iran, aimed to describe the attitude toward smoking and identify the social factors of smoking among students showed that $6.5 \%$ of males had a positive attitude (strong tendency to smoking), $11.8 \%$ of them were either neutral or intermediate and 82.6\% had a negative attitude toward smoking (1).

Exposure to smoke, which is also known as passive smoking, is a serious problem (15). Children as innocent victims are more exposed to tobacco smoke and it is because of the high prevalence of tobacco use in the society, the social and economic problems and subsequently the increased population density in different environments (16).

The WHO reported that approximately half of the children worldwide (about 700 million) are exposed to cigarette smoke and most of this exposure occurs at home. (17). In addition, there is evidence that tobacco smoke exposure is correlated with neurological problems and reduction in academic achievement (18). Based on the reports of US department of health and human services, most of the deaths and illnesses from chronic diseases can be reduced by addressing four major risk factors associated with chronic diseases: tobacco use, diet, activity patterns and alcohol use and these risk factors often originate in childhood and continue into adulthood (19). Exposure to tobacco smoke can raise the risk of respiratory tract infections, media otitis, asthma, allergies, and sudden infant death syndrome (20).

While numerous studies investigated children's exposure to tobacco smoke and its hazards, one aspect is not studied in the literatures yet: "what the children themselves think about smoking, passive smoking and what are their reactions?" (21).

\section{Objectives}

The current study aimed to investigate children's opinion about cigarette smoking and also its role in chronic or degenerative diseases.

\section{Methods}

It was a descriptive study. Population of the study consisted of 148 children aged four to six years randomly selected from eight kindergartens in four areas of Ahvaz) two kindergartens from each area), Iran.
Inclusion criteria were the age of the child, five to six years old, residing in Ahvaz and the capability of mother to attend a session to fill out the questionnaire, ability of child to communicate with his/her mother and answer her questions. This ability includes the complete mental health of the kid.

Data collection tool was a researcher-made questionnaire that its validity was confirmed by the content validity test and its reliability was assessed through a test-retest. After describing goals and methods of the study to the mothers, the questionnaire was given to them; completing the questionnaires through interview with the children was considered as their interest to participate in the study. The reason to select this method was to adhere to the principles of research ethics, satisfaction of parents to become involved in the responses of children and to have answers with mothers' words. Children are more honest with their mothers and also mothers know the best way of effective communication with their own children. In case of delayed questionnaire return, mothers were reminded and if they did not respond, the subject was excluded; $15 \%$ of the questionnaires were missed and not returned.

It is certified that all applicable institutional and governmental regulations concerning the ethical use of human volunteers were followed during this research. Informed written consent was obtained from all participants (mothers of children) and the ethical committee of Ahvaz Jundishapur University of Medical Sciences approved the study in 2015 (under the code: Ir.ajums.rec.1394.267). The study protocol conforms to the ethical guidelines of the 2008 declaration of Helsinki. The statistical significance level was considered 0.05. All statistical analyses were performed by SPSS ver. 22. Descriptive statistics were used to analyze demographic data, Chi-square test for qualitative variables and Pearson correlation coefficient was used to compare quantitative data.

\section{Results}

Descriptive analysis of the study showed that the mean age of participants was five years, $48.9 \%$ female, 52 children (38.8\%) out of 148 were in the first pre-school and $82(61.2 \%)$ were in the second pre-school. Other socio-demographic factors are listed in Table 1; $11.3 \%$ of the participants had respiratory allergies and no significant correlation was found between the allergies and having smoker parents; $56.8 \%$ of the children had smoking relatives or acquaintances; $76.4 \%$ of them knew cigarettes and $41.2 \%$ had a conversation about cigarettes with their parents. There was no significant correlation between knowing and imitation of smoking; $1.4 \%$ asked to buy cigarettes just because of the 
attractive package; $27.8 \%$ of the children imitated smoking and there was a significant relevance between smoking imitation and having a smoker father $(\alpha=0.05)$ but not with a smoker mother; $5.5 \%$ of parents smoked at the presence of their children and $15.1 \%$ outdoors; $62.5 \%$ of them protested to smoking people around. Children's attitude toward smoking showed that $4.1 \%$ of children assumed it good and acceptable while $4.91 \%$ considered it obscene and bad; $1.7 \%$ of children were indifferent towards smoking. There was no significant relevance between their attitudes and mimicking smoking by them. Some of the children's opinions about smoking are listed in Table 2.

Table 1. Personal Findings of the Study

\begin{tabular}{|c|c|}
\hline Personal Findings & No. (\%) \\
\hline \multicolumn{2}{|l|}{ Mean Age } \\
\hline Fathers & 37.89 \\
\hline Mothers & 33.14 \\
\hline \multicolumn{2}{|l|}{ Education } \\
\hline \multicolumn{2}{|l|}{ Father } \\
\hline Non-completed high School & $20(13.9)$ \\
\hline Diploma & $62(43.1)$ \\
\hline Bachelor & $50(33.8)$ \\
\hline University graduate & $12(8.3)$ \\
\hline \multicolumn{2}{|l|}{ Mother } \\
\hline Non-completed high & $28(18.9)$ \\
\hline School & $52(35.1)$ \\
\hline Diploma & $58(39.2)$ \\
\hline Bachelor & $10(6.8)$ \\
\hline University graduate & $11(81.9)$ \\
\hline \multicolumn{2}{|l|}{ Smoking rates } \\
\hline \multicolumn{2}{|l|}{ Father } \\
\hline Non-smoker & 8 \\
\hline Less than 10 cigarettes per day & $16(11.1)$ \\
\hline More than 10 cigarettes per day & $10(6.9)$ \\
\hline \multicolumn{2}{|l|}{ Mother } \\
\hline Non-smoker & $13(94.5)$ \\
\hline Less than 10 cigarettes per day & $8(5.5)$ \\
\hline
\end{tabular}

\section{Discussion}

The current study aimed to describe the attitude of four- to six-year-old children of Ahvaz, Iran, toward cigarettes and smoking. Based on the obtained results,
Table 2. Frequency of Children's Statements About Smoking

\begin{tabular}{|l|l|}
\hline Children's Statements & $\mathbf{N}(\%)$ \\
\hline Smoke has a very bad smell & $15(10.5)$ \\
\hline $\begin{array}{l}\text { God do not like smoking and it's the devil work (the bad guys, } \\
\text { thief, poor, etc.). }\end{array}$ & $11(7.5)$ \\
\hline $\begin{array}{l}\text { Smokers have a stroke or get cancer } \\
\text { Tell smokers not to smoke or they will get sick }\end{array}$ & $27(18.5)$ \\
\hline $\begin{array}{l}\text { Children, whose fathers smoke, are poor because their father } \\
\text { dies early }\end{array}$ & $95(24)$ \\
\hline
\end{tabular}

91.4\% of the children had negative attitude toward smoking on average. A study among pre-school children in Liverpool showed that $91 \%$ of them had negative attitude toward smoking which was consistent with the current study findings. According to the current study results, there was no significant relevance between having smoker parents and pulmonary allergies; but in another study, children with parents smoking more than five cigarettes per day, increased the risk of asthma (2.38\%) in comparison with the parents smoking less than five cigarettes per day or none smoker parents (5). This difference between the current study findings and those of the mentioned studies may be that the current study was not designed to assess the relationship between smoking and pulmonary allergies. Also, based on the current study, 5.5\% of children were exposed to cigarette smoke at home while in a research in Turkey, this rate was $59.9 \%$ (17). Reason for lower rate in Iran may be the cultural differences, importance of child health and beliefs in children rights in the community. In the current research, $76.4 \%$ of children knew cigarettes and one asked to buy cigarettes due to its attractive appearance and packaging. In a study by Dalton et al. by role playing, 50\% of children who bought cigarettes knew about different cigarette types and $17.7 \%$ knew the different brands (22). One of the reasons of this difference between the two studies could be that the main goal in the current study was to assess the knowledge about cigarettes. In Iran, cigarettes are mostly not exposed in the market and buyers should order, but in other countries buyers can pick them from the shelves.

Also based on the results of the current study, there was a significant relationship between having a smoker father and smoking imitation of children. Children start mimicking from two to three years old and learn and keep what they hear or see in their memories (23). Due to parents' crucial role in children's nurture (24), effective educational interventions for parents are suggested, such as training programs on smoking harms in health centers.

In the current study, $62.3 \%$ of children objected to 
smoking cigarettes by their parents or people around and believed that smokers get sick, have stroke and get cancer or die earlier. In the Liverpool research, four- to sevenyear-old children were more sensitive to smoking of people around and in ages of seven to eight were less negative about smoking.

This study showed that, children get used to smoking by others and it seems that they try to accept harmful habits of their parents (20).

Eventually, pre-school or years before pre-school is the best time to educate children about hazards of smoking and cigarettes.

\subsection{Limitations}

The study had some limitations, despite which authors believe that it could be a starting point for psychologists and social physicians to provide a better protocol to help both kids and smoker parents. A number of potential limitations of this study were that it was impossible to interview the kids directly due to lack of collaboration and communication of kids with strangers. It is suggested that future studies have a bigger sample size and to do the same work as an interventional or a quantitative study to achieve more accurate and detailed results.

\section{Acknowledgments}

The current study was granted by the research vice chancellor of Ahvaz Jundishapur University of Medical Sciences. Authors sincerely thank Parvin Abedi, the head of the menopause and andropause research center at Ahvaz Jundishapur University of Medical Sciences for her guidance on writing this article, and also other colleagues who helped to carry out the research. Authors wish to thank families and kindergarten managers who kindly participated in the project.

\section{References}

1. Riahi MA, Aliverdi-nia A, Soleymani-beshli MR. The mail high school student's attitude toward smoking in Qaemshahr. Epidemiol J. 2010;5(3):44-54.

2. Tabib Mohammad Noori Z, Sattari M, Erfanian B. Investigating the relationship between cigarette smoking with TGF- $\beta$ Concentration Ls sulcus fluid of patients with moderate to severe chronic periodontitis. J Dent Sch Shahid Beheshti Univ Med Sci. 1389;28(2).

3. Shvakhi A, Sadeghi R, Minakari M. Effects of opium on the severity of liver damage in patients with chronic hepatitis C and B. IUMS. 2011.

4. Divsalar K, Nakhai N. Smoking prevalence and its relating factors in the students of two universities in Kerman. BMUS. 2009;10(4):78-83.

5. Sharifi L, Poorpak Z, Bokaii S, Karimi A, Movahedi M, Gharagezloo M. The relation between the risk of asthma in children and the number of cigarette the parents smoke in a day, A case control study. TUMS. 2010;67(9):655-60.
6. Agha-molaii T, Zare S. The pattern of smoking cigarette and using hubble bubble in upper 15 years old people in Bandar Abbas, A population study. Hormozgan Med J. 2008;11(4):241-6.

7. Emamghorashi M, Bokaii HR, Keshavarz M. The relation between genetic polymorphism CYP2A6 and the risk of Iranian mens dependence to cigarette [Persian]. Physiol pharmacol. 2009;12(4):296-306.

8. Emami H, Naseri kose Hegrany G, Saeifar K, Rezaei A, Masjedi MR. Study patterns of tobacco smoking and exposure to students [Persian]. Shaheed Sadoughi Med Uni J. 2010;18(2).

9. Seidi J, Shaban M, Sigari N. The effect of cessation of smoking on FEV amount of smokers with chronic obstructive pulmonary disease [Persian]. KUMS. 2007.

10. Shaokohi S, Babanejad M, Biranvand R, Behzadifar M, Delpisheh A. Evaluation of risk factors for cardiovascular disease in the elderly Ilam in 1390 [Persian]. SBMU. 2012(4):94.

11. Ramezankhani A, Sarbandi Zaboli F, Zarghi A, Heydari G, Masjedi MR. Smoking cigarette pattern in teenage students in Tehran [Persian]. SBMU. 2011;15(3):115-22.

12. Rezaii F, Majdzade SR, Nejat S, Golestan B. A qualitative study of the reasons of 13 to 15 years old boys' tendency toward cigarette in Tehran [Persian]. HHMI. 2008;5(4):25-33.

13. Sharifi-rad GH, Hezaveii MM, Hasanzade A, Daneshamooz A. The effect of health education According to health belief model on smoking preventive functions in high school students [Persian]. Arak Med Uni Med. 2008:161-88.

14. Aliverdi-nia A, Riahi MA, Soleymani-beshli MR. Sociological Specification of tendencies toward smoking [Persian]. Literature Hum colleage. 2009;16(61):161-88.

15. Delaram M, Sereshti M. Relation between indirect smelling of cigarette smoke in mothers and the infant weight at the time of birth [Persian]. QUMS. 2007;10(1):67-71.

16. Albalbaki M, Moradi A, Davoodi M, Farhanchi A, Sanatkarfar M. Acute respiratory complications during anesthesia in children with involuntary exposure to tobacco smoke [Persian]. JRHS. 2009;15(2):36-41.

17. Ekerbicer H, Celik M, Guler E, Davutoglu M, Kilinc ME. Evaluating environmental tobacco smoke exposure in a Group of Turkish primary school students and developing intervention methods for prevention. BMC Public Health. 2007;7(202).

18. Robinson J, Kirkcaldy AJ. 'Imagine all that smoke in their lungs': parents' perceptions of young children's tolerance of tobacco smoke. Health Educ Res. 2009;24(1):11-21. doi: 10.1093/her/cym080. [PubMed: 18156146].

19. US Department of Health and Human Services. . The health consequences of smoking: A report of the surgeon general. 2004.

20. Woods SE, Springett J, Porcellato L, Dugdill L. 'Stop it, it's bad for you and me': experiences of and views on passive smoking among primary-school children in Liverpool. Health Educ Res. 2005;20(6):645-55. doi: 10.1093/her/cyh027. [PubMed: 15829496].

21. Porcellato L, Dugdill L, Springett J, Sanderson FH. Primary schoolchildrens' perceptions of smoking: implications for health education. Health Edu Res. 1999;14(1):71-83.

22. Dalton MA, Bernhardt AM, Gibson JJ, Sargent JD, Beach ML, AdachiMejia AM, et al. Use of cigarettes and alcohol by preschoolers while role-playing as adults: "Honey, have some smokes". Arch Pediatr Adolesc Med. 2005;159(9):854-9. doi: 10.1001/archpedi.159.9.854. [PubMed: 16143745].

23. Nutrition and health publication . Bishop's properties and applications 2012. Available from: http:// www.rasekhoon.net.

24. Vardavas CI, Athanasopoulos D, Balomenaki E, Niaounaki D, Linardakis MK, Kafatos AG. Smoking habits of Greek preschool children's parents. BMC Public Health. 2007;7:112. doi: 10.1186/1471-2458-7-112. [PubMed: 17570836]. 